\title{
Why Does Anyone Mediate if Mediation Risks Psychological Dissatisfaction, Extra Costs and Manipulation? \\ Three Theories Reveal Paradoxes Resolved by Mediator Standards of Ethical Practice
}

\author{
SAMUEL J. IMPERATI AND STEVEN M. MASER
}

\begin{abstract}
Three paradoxes afflict mediation. First, if self-determination is a psychological need motivating the parties and the mediator, how can the parties and the mediator jointly satisfy their potentially conflicting needs? Second, if parties are having difficulty resolving their conflicting individual interests and incurring costs in the process, why would they invite a third party into the conflict who has his or her own interests and adds costs? Third, if it is impossible to guarantee that any collaborative decision making process can be immune to manipulation by one of the participants, including the mediator, why would parties expose themselves to the risks of mediation? Three mutually reinforcing theories (Self-Determination Theory, Transaction Resource Theory, and Collective Choice Theory) reveal these paradoxes. The analysis demonstrates how professional organizations and states can resolve the three paradoxes by crafting and enforcing mandatory standards of ethical practice for mediators.
\end{abstract}

\section{INTRODUCTION}

We know how mediation works. ${ }^{1}$ Do we know why? This paper proposes an affirmative answer by drawing upon theories from the fields of Psychology, Economics, and Political Science. However, these theories reveal three paradoxes, leading us to question why anyone, including a mediator, would engage in mediation. If anyone does, we conclude, it will be because standards of ethical practice resolve the paradoxes.

\footnotetext{
* Authors listed in alphabetical order: Samuel J. Imperati, J.D.: Executive Director Institute for Conflict Management, Inc. Portland, Oregon.

Steven M. Maser: Professor Emeritus of Public Policy and Public Management Atkinson Graduate School of Management Willamette University, Salem, OR.

${ }^{1}$ See Robert H. Mnookin, Why Negotiations Fail: An Exploration of Barriers to Resolution of Conflict, 8 OHIO ST. J. ON DISP. RESOL. 235, 248-49 (1993).
} 
First, from the field of psychology, mediators are called upon to help resolve a conflict among self-determining parties who choose their own dispute resolution processes and make their own substantive agreements. ${ }^{2} \mathrm{~A}$ mediator is also a self-determining actor with, among other things, a reputational stake in promoting her settlement prowess, a desire to "balance power," or a desire to ensure the "right" outcome is achieved. Those interests may or may not be compatible with interests of the parties in any given mediation. Would this not give self-determining parties pause about participating in mediation? Indeed, would this not give a self-determining third-party pause about serving as a mediator?

Second, from the field of economics, parties negotiating a resolution engage in a costly mixed motive game that involves conflicting incentives to cooperate or compete. Bringing in a third party, the mediator, to assist them introduces a second, costly, mixed motive game: this one between the parties and the mediator, who wants the parties to settle to advance his or her own interests. Would this not give each party and the mediator pause?

Third, from the field of political science, it is not possible to design a process for translating individual parties' preferences into a group preference that assures against the parties cycling interminably from one proposed agreement to another. ${ }^{3}$ Even if they settle on one, the parties, and the mediator could still have "manipulated" the process. Would this not give each party and the mediator pause?

Given these three paradoxes, the surprise is not that mediation works as well as it does. The surprise is that people mediate at all, even though mediation's proponents believe it is much better than litigation in terms of satisfying the overall interests of the participants. ${ }^{4}$ That mediation happens is testimony to the mediator's judicious application of ethical rules and rhetoric to serve the participants'-including the mediator's-psychological needs for self-determination and for economizing on the costs of negotiating.

Judicious here means being ethical. The mediator who adheres to wellcrafted standards of practice resolves the triple paradox, improving the parties' confidence and willingness to engage in the process. Given the power inherent in the mediator's role, everyone's perception that the mediator will behave ethically gives force to, and trust in, the process.

${ }^{2}$ SUSAN RAINES, CONFLICT MANAGEMENT FOR MANAGERS 100-01 (2013).

${ }^{3}$ KenNETh ARROW, Social ChOICE AND INDIVIDUAL VALUES 11 (2d ed. 1963).

${ }^{4}$ This is conventional wisdom. See Using Mediation in Your Lawsuit, IDloT's GUIDES, http://idiotsguides.com/static/quickguides/politicalsciencelaw/using-mediationin-your-lawsuit.html (last visited Mar. 25, 2014). 
We base this argument on three theories. Like mediation itself, they originate in different disciplines. They reinforce each other to expose common assertions ${ }^{5}$ about mediation practice that are arguably erroneous: A) parties own the outcome; mediators own the process, and B) mediators have no preferences over outcomes.

Section II of this paper outlines the three theories (Self-Determination Theory, Transaction Resource Theory, and Collective Choice Theory), the resulting paradoxes, and associated remedial standards of ethical practice. We will refer to the guidelines embodied in the Oregon Mediation Association Core Standards of Mediation Practice (OMA Standards in the following text) for resolving them. ${ }^{6}$ Our analysis allows us to derive criteria ${ }^{7}$ for standards of practice that can breed more confidence in mediation, much as a reputation can breed more confidence in a particular mediator.

"These assertions may be a result of the "availability cascade" cognitive bias. It is the "self-reinforcing process in which a collective belief gains more and more plausibility through its increasing repetition in public discourse (or, repeat something long enough and it will become true)." See Timur Kuran \& Cass R. Sunstein, Availability Cascades and Risk Regulation, 51 STAN. L. REV. 683 (1998).

6 See generally OREgon MEdiATION AsSOCIATION, OREgON MEDiation ASSOCIATION CORE STANDARDS OF MEDIATION PRACTICE (2005), available at http://www.omediate.org/pg61.cfm. The American Arbitration Association, American Bar Association, and the Association for Conflict Resolution (ACR) adopted their "Model Standards of Conduct for Mediators" ("Joint Code") in 2005 as well. MODEL STANDARDS FOR MEDIATORS (American Arbitration Ass'n et al. eds., 2005), available at http://www.acrnet.org/uploadedFiles/Practitioner/ModelStandardsofConductforMediators final05(1)(1).pdf. The Oregon Mediation Association changed many of its provisions when adopting the OMA Standards to add further detail and qualify some of the practical challenges it believed the Joint Code created for the practitioner in the field. The authors suggest both codes should be modified to attend to the issues raised herein.

OREGON MEDIATION ASSOCIATION, supra note 6, at 1.The OMA Standards Preamble notes the complexity and diversity of the field with, "These Core Standards recognize that the role of mediator is complex, individual practice areas vary, and a full spectrum of personal, professional, and cultural diversity surrounds mediator approaches. These differences are valuable. These Core Standards should not be construed to favor or disfavor any particular approach." Id. Because mediation is evolving, the Preamble also notes its provisions "are not intended to dictate conduct in a particular situation, define 'competency,' establish 'best practices,' or create a 'standard of care.' They are not intended to be disciplinary rules." $I d$. Finally, the Preamble recognizes the interdisciplinary nature of the field. It states, "When these Core Standards conflict with or are silent on subjects covered by applicable laws, regulations, professional licensing rules, professional ethical codes, or contracts by which the mediator may be bound, mediators should be aware and make participants and others in attendance aware that those requirements may take precedence over these Core Standards." $1 d$. 
First, self-determination theory (SDT) explains the motivation for anyone to participate in mediation. ${ }^{8}$ In our application of SDT to mediation, it is not that the parties necessarily trust the mediator, who empowers and protects them so they can reveal information essential for satisfying their underlying interests. Rather, mediating helps the parties and the mediator satisfy their innate psychological needs for competence, autonomy, and relatedness, which are necessary conditions for their psychological growth, integrity, and well-being. Second, transaction resource theory (TRT) explains the conditions under which parties will turn to a third-party to explore resolution. ${ }^{9}$ In our application of TRT to mediation, reaching agreement requires each individual to deal with contradictory pressures. They are: A) the costs of making concessions and complying with the terms of an agreement (militate against making an agreement) versus B) the benefits of reducing conflict and inducing others to cooperate (militate in favor of making it.) Mediators can supplement the resources parties exhaust in managing these pressures, even after accounting for the costs of introducing the mediator. Third, collective choice theory (CCT) explains the impossibility of guaranteeing against someone manipulating the process when members of a group, such as two or more parties in conflict with the addition of a mediator, attempt to reach agreement be it on process or substance. ${ }^{10}$ In our application of CCT to mediation, a mediator's involvement in defining the process and in framing or reframing arguments and proposals cannot avoid being manipulative. CCT identifies the conditions under which parties could condone this.

Section III of this paper outlines the strategic "manipulations" that are tools of the mediator's trade: A) Heresthetics (Politics), and B) Rhetoric (Persuasive Discourse). We discuss them in the context of SDT, TRT and $\mathrm{CCT}$, and the applicable ethical standards.

Section IV outlines recommendations to assist organizations setting out to create and revise their standards of conduct. We also argue for changing most, if not all, mediator standards from guidelines to enforceable expectations of conduct.

${ }^{8}$ See generally Edward L. Deci \& Richard M. Ryan, The "What" and "Why" of Goal Pursuits: Human Needs and the Self-Determination of Behavior, 11 PSYCHOL. INQUIRY 227, 227-268 (2000).

${ }^{9}$ See Jules Coleman et al., A Bargaining Theory Approach to Default Provisions and Disclosure Rules in Contract Law, 12 HARV. J. L. \& PUB. POL'Y 639, 681-82 (1989).

${ }^{10}$ See JOHN BONNER, POLITICS, ECONOMICS AND WELFARE: AN ELEMENTARY INTRODUCTION TO SOCIAL CHOICE 59-60 (1986). 


\section{TheORIES, PARADOXES AND STANDARDS OF PRACTICE}

We provide the following overview table ${ }^{11}$ of the theories, paradoxes and associated ethical practices:

\begin{tabular}{|c|c|c|c|}
\hline & Theory & Paradox & Ethics \\
\hline A) & $\begin{array}{l}\text { Self- } \\
\text { Determination } \\
\text { Theory }\end{array}$ & $\begin{array}{l}\text { The more the mediator } \\
\text { maximizes the parties' } \\
\text { self-determination, the } \\
\text { less the mediator satisfies } \\
\text { her own. }\end{array}$ & $\begin{array}{l}\text { Self- } \\
\text { Determination } \\
\text { Informed } \\
\text { consent }\end{array}$ \\
\hline B) & $\begin{array}{l}\text { Transaction } \\
\text { Resource } \\
\text { Theory }\end{array}$ & $\begin{array}{l}\text { Parties exhaust their } \\
\text { transaction resources in } \\
\text { resolving their individual } \\
\text { interests, yet they invite a } \\
\text { third party into the } \\
\text { conflict with his or her } \\
\text { own interests. }\end{array}$ & $\begin{array}{l}\text { Impartial } \\
\text { Regard } \\
\text { Confidentiality }\end{array}$ \\
\hline C) & $\begin{array}{l}\text { Collective } \\
\text { Choice } \\
\text { Theory }\end{array}$ & $\begin{array}{l}\text { It is impossible to design a } \\
\text { process for translating } \\
\text { individual parties' } \\
\text { preferences into a group } \\
\text { preference that guarantees } \\
\text { the parties will not cycle } \\
\text { interminably among } \\
\text { possible outcomes. }\end{array}$ & $\begin{array}{l}\text { Self- } \\
\text { Determination } \\
\text { Impartial } \\
\text { Regard } \\
\text { Good-Faith } \\
\text { Participation } \\
\text { Informed } \\
\text { Consent }\end{array}$ \\
\hline
\end{tabular}

Table 1

"See supra notes 8-10. See also infra notes 13, 48, 92-96, and accompanying text. 


\section{A. Self-Determination Theory and Paradox 1}

Self-determination is a cornerstone of mediation. ${ }^{12}$ What does "selfdetermination" mean? To Bush and Folger, it means a relational concept of human identity based on two perceptions:

As a matter of basic human consciousness, every person senses that he or she is a separate, autonomous agent authoring her or his own life, and at the same time senses that that he or she is an inherently social being, connected to other people in an essential and not just instrumental fashion. $^{13}$

We read this to mean, to the extent that conflict diminishes an individual's perceptions of his or her autonomy and connectedness, it compromises the individual's sense of identity. This deficit motivates the individual's effort to change the conflict interaction, with or without a third party's assistance, to try to regain a sense of humanity.

Bush and Folger's description of self-determination is problematic. They use the terms "individual agency" and "individuality" to explain what they mean by "separate, autonomous agent, authoring his or her own life." This confounds the notion of an individual's psychological need for a sense of "independence," meaning distinctiveness, with the notion of an individual's psychological need for a sense of "volition," meaning ability to choose. What Bush and Folger mean by "connected to other people in an essential . . . fashion" is less clear, but apparently, it has to do with a need for an "understanding between human beings." 14 This confounds the notion of an individual's psychological need to have a sense of belonging with an individual's psychological need for empathy.

Self-Determination Theory, a well-articulated, internally coherent, and empirically grounded theory of human psychology corrects these confounds. ${ }^{15}$ It improves the foundation on which mediation practice can build. Its precepts are:

${ }^{12}$ Samuel J. Imperati et al., If Freud, Jung, Rogers and Beck Were Mediators, Who Would the Parties Pick and What are the Mediator's Obligations?, 43 IDAHO L. REV. 645,647 (2007).

${ }^{13}$ Robert A. Baruch Bush \& Joseph P. Folger, Transformative Mediation: Theoretical Foundations, in TRANSFORMATIVE MEDIATION: A SOURCEBOOK 22 (Joseph P. Folger et al. eds., 2010).

${ }^{14}$ Dorothy J. Della Noce, Seeing Theory in Practice: An Analysis of Empathy in Mediation, 15 NEGOTIATION J. 271, 273 (1999).

${ }^{15}$ Deci \& Ryan, supra note 8, at 227-68. 
- the natural orientation of humans is to grow, integrating their psychic elements into a unified sense of self and into larger social structures;

- acting on the environment rather than passively awaiting a disequilibrium; ${ }^{16}$

- extrinsic rewards and other environmental conditions catalyze selfmotivation; and

- psychological well-being to the extent that they satisfy innate psychological needs. ${ }^{17}$

Consistent with Bush and Folger, Deci and Ryan define a psychological "need" as an organismic necessity, neither an acquired motive nor learned. ${ }^{18}$

In contrast to Bush and Folger, who imply two needs, Deci and Ryan posit three: ${ }^{19}$

- Competence is "a propensity to have an effect on the environment as well as to attain valued outcomes within it." ${ }^{, 20}$ It speaks to senses of efficacy and mastery.

- Relatedness "refers to the desire to feel connected to others-to love and care, and to be loved and cared for." ${ }^{21}$ It speaks to senses of belonging and security.

- Autonomy "refers to volition-the desire to self-organize experience and behavior and to have activity be concordant with one's integrated sense of self."22 As opposed to a sense of being in control or independent, it speaks to the senses of freedom and inner coherence. ${ }^{23}$

The degree of need can differ from person to person. For psychological growth, integrity, and well-being, people require psychological nutrients for all three; satisfying one or two is not sufficient. ${ }^{24}$ Different individual goals and processes are associated with different degrees of need satisfaction; the needs themselves are universal, if not invariant. ${ }^{25}$ Satisfying these needs intrinsically motivates behavior without requiring separable consequences. ${ }^{26}$

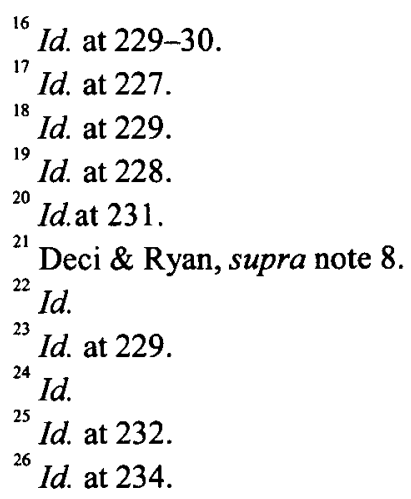


Thus, a party in mediation who appears to be pursuing self-interest in terms of an extrinsic outcome, like maximizing a payout, is expressing an intrinsic need for competence: to have an effect on the environment and to attain a valued outcome within it. A party who appears to be righting a wrong, exacting retribution, or seeking fairness can be expressing a need for relatedness, to feel connected to others, or autonomy; "to have [an] activity be concordant with one's integrated sense of self." a mediator might ask one party to be "fairer" than another party, to take the higher ground, if you will.

In these terms, the goal of mediation is to satisfy the parties' innate needs, eliciting by their own actions an agreement to which they can commit, effectuate, and, ideally, improve their relationship.

The adversarial process in a judicial setting compromises the parties' self-determination. It undermines their feeling competent because it requires agents with legal expertise. It undermines their feeling related because it alienates the parties. It undermines their feeling autonomous because decisions by others largely control the process and the outcome. Mediation, in contrast, provides ambient supports for the parties to experience competence, relatedness, and autonomy because they control the process and outcome.

This brings us to the first of three paradoxes bedeviling mediation: the more a mediator maximizes the parties' self-determination, the more the mediator appears to minimize his or her own. Mediators are selfdetermining, too. They talk about solving problems, which speaks to a need for competence; about being held in high regard and helping others, which speaks to a need for relatedness; and about improving situations and adding value, which speaks to a need for autonomy, that is, a sense of volition. If the parties determine the process and the outcome, for example, then the mediator does not, diminishing the mediator's sense of competence, relatedness, and autonomy. ${ }^{28}$ This would seem to be a source of ambivalence

${ }_{28}^{27}$ Deci \& Ryan, supra note 8, at 231.

${ }^{28}$ This dynamic comes into focus when the mediator uses caucuses. Information control, presentation of arguments, and case evaluation are partially transferred from the parties to the mediator. The situation is further complicated by the mediator's confidentiality obligations. They prevent her from disclosing all of the facts and perspectives that are influencing her selective disclosures and evaluation. In essence, the mediator is saying, "trust me-I'm a smart and ethical professional." However, this creates the opportunity for manipulation, even if usually benevolent, and can lead to distrust of shuttle diplomacy. The return to a joint session only model can be a de facto minimization of the mediator's self-determination. It is, however, more consistent with the societal megatrend of transparency in decision-making. See Jeffrey Makoff \& Jessica 
for the mediator, and therefore for the parties about engaging in mediation. How, then, to resolve the paradox?

First, organizations that promote mediation operationalize SDT in their standards and in the comments that elucidate each one. The Oregon Mediation Association's Standard 1 is labeled "Self-Determination." It reads, "Mediators respect, value, and encourage the ability of each participant to make individual decisions regarding what process to use and whether and on what terms to resolve the dispute." ${ }^{29}$ Comment 1 following Standard 1 captures what Deci and Ryan mean by autonomous, defining "selfdetermination" to mean that participants "should be free to choose their own dispute resolution process, and mediators should encourage them to make their own decisions on all issues.",30

Comment 2, while making the participants' autonomy explicit, operationalizes Deci and Ryan's notion of relatedness by using the phrase "collaborative interaction." The Comment states, "Mediators respect the culture, beliefs, rights, and autonomy of the participants. Mediators should defer their own views to those of the participants ... recognizing that the collaborative interaction between the participants is often the key to resolution." ${ }^{31}$ Comment 5 references the benefits of the process and a potential agreement, one of which is to improve the relationship between the parties, reinforcing relatedness: "Mediators should encourage participants to consider the benefits of mediation and agreement, as well as the consequences of non-participation and non-agreement.,"32

By introducing the notion of "Informed Consent," Comments 3, 4 and 6 operationalize Deci and Ryan's notion of competence.

3. Mediators should educate participants about the continuum of mediation approaches ${ }^{34}$ and identify the approaches the mediator

Grynberg, "Private Caucusing" In Civil Pretrial Mediations, MEDiATE.CoM, http://www.mediate.com/articles/MakoffJ1.cfm (last visited Mar. 25, 2014).

${ }^{29}$ OREGON MEDIATION Association, supra note 6, at std. I.

${ }^{30} \mathrm{Id}$. at $\mathrm{cmt}$. 1 .

${ }^{31}$ Id. at cmt. 2.

${ }^{32} I d$. at cmt. 5 .

${ }^{33}$ Id. Standard II, Informed Consent, states, in part, "To fully support SelfDetermination, mediators respect, value, and encourage participants to exercise Informed Consent throughout the mediation process. This involves making decisions about process, as well as substance, including possible options for resolution ...." Id.

${ }^{34}$ Id at std. 1, cmt. 3. The term "Approach" is used in these Core Standards to signify “... the behaviors, philosophies, processes, styles, and techniques used by mediators to conduct mediation." Id. 
practices. Engaging the participants in a discussion to establish expectations about these approaches will help the participants give their Informed Consent to the approach best suited for their particular situation.

4. While a mediator cannot ensure that participants are making informed and voluntary decisions, mediators should help participants understand the process, issues, and options before them and encourage participants to make informed and voluntary decisions. . .

6. Participation in mediation is usually a voluntary process. Even when mediation is "mandatory," participants who are unable or unwilling to participate effectively in the mediation process should be free to suspend or withdraw from mediation. Mediators should respect a participant's informed decision to continue or end the process. ${ }^{35}$

Indeed, Comment 5 on Standard 2, "Informed Consent," directs mediators to "make ongoing, good-faith efforts to assess the freedom and ability of each participant to make choices..." and to "suspend, end, or withdraw from the mediation if they believe a participant is unable to give 'Informed Consent." ${ }^{, 36}$ If the OMA's standards of practice operationalize selfdetermination for the parties, how do they reconcile this with selfdetermination for the mediator?

First, Comment 2 on Standard 1 directs mediators to subordinate their "views." ${ }^{37}$ If Deci and Ryan are correct, mediators can more easily subordinate their views, which are mechanisms to satisfy their three needs, than they can subordinate those needs, which drive mediators psychologically as much as they do everyone else. Additionally, according to OMA Standard 3, the mediator should decline to serve or withdraw if it requires sufficient subordination to affect their "Impartial Regard."38 OMA standards in effect advise the mediator and the parties that the mediator will satisfy his or her needs by reinforcing the self-determination of the parties.

Second, Standard 2 on informed consent not only acknowledges that mediators have needs; it also creates the expectation that each party will engage the mediator on the mediator's terms, but only with consent. ${ }^{39}$ It directs the mediator to secure each party's informed consent to use the specific mediator and the mediator's articulated approach to mediation. It says, "Initially and throughout the mediation process, mediators further support Self-Determination by making appropriate disclosures about themselves and the specific mediation

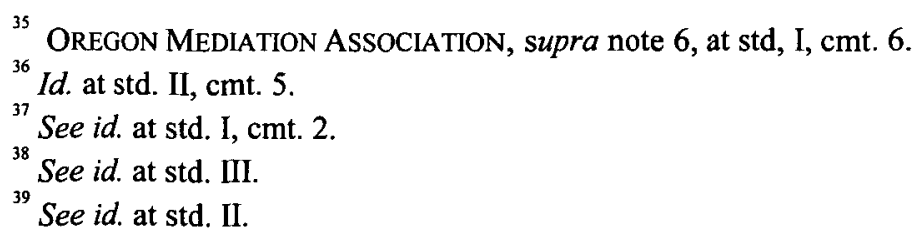


approaches they use. ${ }^{, 40}$ Comment 4 on Standard 2 directs mediators to "... disclose information regarding conflicts of interest, fees, relevant relationships, process competency, and substantive knowledge of the subject matter in dispute. Mediator disclosure should be truthful and not misleading by omission." ${ }^{, 41}$ Presumably, informed participants will select a different mediator or a different process if they decide that the mediator, as indicated in these disclosures, will jeopardize their individual and collaborative goals. If they do not make an alternative selection, then by implication, the mediation can proceed in ways that address the mediator's needs without his or her subordinating them to the needs of the parties.

Third, mediators have a say in this. Standard 5, "Process and Substantive Competence," directs them to "mediate only when they offer the desired approach and possess the level of substantive knowledge, skills and abilities sufficient to satisfy the participants' reasonable expectations. ${ }^{, 42}$ Comment 1 on this Standard directs mediators to "exercise their independent judgment when their abilities or availability are unlikely to satisfy the participants' articulated expectations." ${ }^{43}$ Mediators make their own determinations to mediate as autonomous actors, based on their competent judgment, and the nature of relationships with the parties, but only after Informed Consent. Indeed, this Comment would be more helpful if it clarified what it means when it says that mediators should "consider factors such as the participants involved . . ." when exercising their independent judgment. ${ }^{44}$ Because another factor is ". . . their agreed-upon mediation approach," this direction acknowledges, if not addresses, the mediator's need for relatedness and acknowledges the professional goal of subordination to the participants. In sum, OMA's Standards recognize and operationalize everyone's need for self-determination, including mediators', resolving the first paradox, but why not make this point more specifically and provide more guidance in the Comments?

\section{B. Transaction Resource Theory and Paradox 2}

What, though, do the parties in conflict expect mediators to do? What should mediators do? For answers, we turn to transaction resource theory

\footnotetext{
${ }^{40} I d$.

${ }^{41}$ OREgon Mediation Association, supra note 6, at std. II, cmt. 4.

${ }^{42}$ Id. at std. $\mathrm{V}$.

${ }^{43}$ Id. at std. $\mathrm{V}$, cmt. 1.

${ }^{44}$ Id.

${ }^{45}$ Id.
} 
(TRT), which is informed by the economics of information, by the gametheoretic structures of most conflicts, and, therefore, by the parties' incentives. ${ }^{46} \mathrm{We}$ apply TRT to both substantive and process agreements, including agreements to mediate. It predicates that people incur transaction costs to overcome imperfect information. ${ }^{47}$ The imperfections derive from complex mixtures of what Max Weber terms "opposed and complementary interests" in-group decision-making. ${ }^{48}$ These place distinct information demands on the parties.

We characterize the relationship among disputants as a configuration of individual interests called a divisible prisoner's dilemma game. In the simple prisoner's dilemma game, parties negotiating on their own know that cooperating to find a mutually agreeable solution can yield a better outcome than not cooperating. ${ }^{49}$ However, each party also has an incentive to act in a self-interested way that undermines cooperation if the other party cooperates, which generates the best result for the non-cooperator and the worst result for the cooperator. ${ }^{50}$ Simply stated, they do not trust each other, so the incentive not to cooperate prevails. ${ }^{51}$

This presents its players with two decision-making problems: (1) coordination, wherein individuals identify mutually beneficial processes and outcomes and synchronize their behavior to attain them; and (2) defection, wherein the parties deter free-riding so that an individual acting in his or her own self-interest will not get discordant and jeopardize the parties attaining mutual benefits. ${ }^{52}$ The divisible prisoner's dilemma incorporates a third decision-making problem: division, wherein members of the group must bargain to allocate among themselves the benefits and risks of cooperating. ${ }^{53}$ The divisible prisoner's dilemma is a richer and more realistic model of relationships in conflict.

Each of the three decision-making problems creates distinct informational demands ${ }^{54}$ People expend resources on searching for

${ }^{46}$ See generally Coleman et al., supra note 9.

${ }^{47}$ See id. at 651.

${ }^{48}$ MAX WEBER, THE THEORY OF SOCIAL AND ECONOMIC ORGANIZATION 136 (Talcott Parsons \& A.M. Henderson trans., 1947) ("The purest cases of associative relationships are: (a) rational free market exchange, which constitutes a compromise of opposed but complementary interests .....").

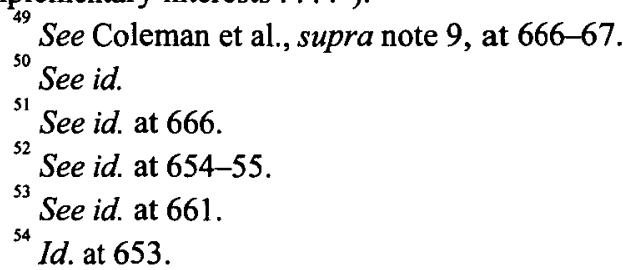


alternatives when they do not know which ones create gains, that is, are feasible; on bargaining when they do not know which ones they can agree to as equitable; and on monitoring when they do not know which ones are enforceable. ${ }^{55}$ In a coordination problem, the parties share a common interest, which encourages them to pool whatever relevant knowledge they each possess to identify the best plan for cooperating to find a solution to the conflict. ${ }^{56}$ When coordination combines with division problems, communications can no longer be taken at face value ${ }^{57}$ Bargainers benefit from suppressing or distorting information about potential process options and substantive outcomes ${ }^{58}$ For example, exaggerating the value of their own alternatives or understating the value of alternatives available to the opponent. When coordination problems combine with enforcement problems, more difficulties arise. The problem of deterring defection from agreement is compounded by two other problems: 1) identifying enforcement mechanisms that are sufficiently expansive and efficient to plug loopholes, but also restrictive enough to deter defection, and 2) allocating the cost of enforcement. ${ }^{59}$ Each of the problems can vary in magnitude.

To resolve the defection problem, the parties create a "force of agreement." ${ }^{60}$ That is, they either block opportunities to defect or impose disincentives that are sufficient to deter defection. ${ }^{61}$ The parties can only secure gains from cooperating if they can agree first on the terms for sharing the cost of creating and maintaining the enforcement system. The simple prisoner's dilemma game during conflict becomes a sequence of bargaining games. ${ }^{62}$ The parties will be unsure about agreeing on terms without first agreeing on a force of agreement, ${ }^{63}$ but also unsure about agreeing on a force

${ }^{55}$ See Coleman et al., supra note 9 , at 657

${ }^{56}$ See id. at 654-55.

${ }^{57}$ Id.

${ }^{58}$ Id.

Id. at 666 .

${ }^{60}$ Id. at 669.

${ }^{61}$ Coleman et al., supra note 9 , at 668 .

${ }^{62}$ Id. at 672 .

${ }^{63}$ This is less of a concern when mediating within the shadow of the court system where enforcement mechanisms are already in place. It is more an issue for public policy cases that are mediated in the shadow of the political process where elected or appointed third parties often decide whether to accept, implement, and enforce mediated agreements. A mediator typically leads disparate parties to prepare recommendations for a sponsor who has the authority to implement them. The more the parties can rely upon the sponsor to act consistent with the parties' recommendations, the more the parties can focus on the substantive deal. 
of agreement when they do not know whether they will be able to reach agreement on terms. ${ }^{64}$

Consistent with SDT, we assume that people prefer to resolve these problems on their own. We also assume that people usually have transaction resources among themselves to resolve these problems without involving a third party. Transaction resources include communication channels, sources of information, information processing capacities, time, money, and the ability to monitor compliance and sanction noncompliance. ${ }^{65}$

The demand for third-party involvement, including mediation or courts, arises where relationships are so complex or otherwise fraught that limitations in the group's stock of available transaction resources block process or substantive agreement. ${ }^{66}$ For example, the parties have insufficient information to overcome their distrust for each other, or to avoid psychological traps that result from their cognitive limitations such as the Availability Heuristic ${ }^{67}$ or the Over-confidence Effect. ${ }^{68}$ Addressing these insufficiencies and traps drain their stock of transaction resources.

A third party can augment the transaction resources already present in the relationship, or it can provide resources that are deficient. ${ }^{69}$ Judicial institutions, however costly they may be, can be more efficient at enforcing agreements than self-enforcement. ${ }^{70}$ By relying on precedent, for example, the courts create predictability in resolving disputes so parties can devote their scarce transaction resources to making substantive agreements. A mediator can improve communication to help the parties identify solutions. ${ }^{71}$ In our experience, unlike a judge, a mediator usually is not authorized to enforce an agreement, but a selected mediator brings resources that an assigned judge might not: substantive expertise, expert risk evaluation, creativity, party face-saving, and more time to attend to the parties' psychological reactions.

In theory then, parties in conflict demand different types and degrees of intervention (facilitation, mediation, arbitration, litigation) depending on the

${ }^{64}$ Coleman et al., supra note 9 , at 672-73.

${ }^{65}$ Id. at $679-80$.

${ }^{66}$ Id. at $681-82$.

${ }^{67}$ See generally Amos Tversky \& Daniel Kahneman, Availability: A Heuristic for Judging Frequency and Probability, 5 COGNITIVE PSYCHOL. 207 (1973).

${ }^{68}$ See generally HEURISTICS AND BIASES: THE PSYCHOLOGY OF INTUITIVE JUDGMENT (Thomas Gilovich, Dale Griffin, \& Daniel Kahneman eds., 2002).

${ }^{69}$ Coleman et al., supra note 9 , at 682.

${ }^{70}$ Id. at 681 .

${ }^{71}$ Id. at 682 . 
deficiency in their internal transaction resources. ${ }^{72}$ This can range from relatively passive facilitators who keep time and encourage individual participation, to relatively aggressive problem-solvers who propose agreements. ${ }^{73}$ Consistent with SDT, effective mediators craft their interventions to remedy the specific deficiencies in the transaction resources among the particular parties, which is what generates an expectation by the parties that a mediator can help them.

This brings us to the second of three paradoxes bedeviling mediation: introducing a third-party creates a second divisible prisoner's dilemma game, one between the mediator and the parties in conflict, with resulting increased transaction costs. Restated, parties exhaust their transaction resources in resolving their individual interests, yet they invite a third party into the conflict with his or her own interests. Before the mediator begins mediating, the parties, including the mediator, should agree on the approach to mediation (e.g., transformative, facilitative, or evaluative), which requires its own force of agreement. Everyone, including the third-party, has an incentive to cooperate in selecting and following a process for finding an agreeable solution, if one exists. However, everyone, including the mediator, has opportunities to behave in a self-interested manner that could undermine cooperation. For instance, the parties might benefit from an evaluative approach but the mediator being considered does not practice it. ${ }^{74}$

The range of transaction resources the mediator brings to the table becomes his or her source of power, not only during the mediation, but also in the decision about process. ${ }^{75}$ In this view, the mediator's power, authority, and legitimacy derive from the value the parties in conflict place on the mediator's transaction resources. ${ }^{76}$ The question is what are the conditions, if any, under which all parties, including the mediator, would agree that the mediator may exercise independent judgment because it is in all of their interests for this to happen? ${ }^{77}$

Asked in terms of OMA's standards, when might the parties give their informed consent, consistent with Standard 2, to a mediator exercising independent judgment, such as being a type of evaluative mediator,

${ }^{72}$ See id. at $685-86$.

${ }^{73}$ See id.

${ }^{74}$ To the extent that mediation is more art than science, successful mediators bring their experience and discerning wisdom to the table, often as "advocates for resolution." Parties often consider this a "value-added" proposition.

${ }^{75}$ See Coleman et al., supra note 9 , at 683 .

${ }^{76} \mathrm{Id}$.

${ }^{n}$ See generally Omer Shapira, A Theory of Sharing Decision-Making in Mediation, 44 MCGEORGE L. REV. 923 (2013). 
remaining consistent with Standard 3 on Impartial Regard? ${ }^{78}$ TRT asks, what constitutes "full" and "informed?" more informed the parties become, the more costly it is and the less likely they are to participate in mediation. Mediators have to balance their behavior, as OMA's standards direct. ${ }^{80}$

This is a basic coordination problem between the mediator and the parties. ${ }^{81}$ The solution is the behavior preferred by everyone that allows a mediator to function, applying his or her transaction resources. Moreover, a mediator's ability to terminate the mediation, just like each party's ability to withdraw from it, provides a force of agreement that helps to resolve the divisible prisoner's dilemma between the mediator and the parties.

OMA's Standards capture this in Standard 3: Impartial Regard, and Standard 4: Confidentiality. ${ }^{82}$ If they act in accord with Standard 3, mediators will conduct mediations, "diligently, even-handedly, and with no personal stake in the outcome." 83 Standard 3 does not call for the mediator to be "neutral" or "impartial," because they have points of view. The Standard focuses on the mediator's behavior even though it does not define what it means by mediating "even-handedly." 84 This is not unusual and it affords mediators a degree of discretion. ${ }^{85}$ Comments 1 and 2 require the mediator to identify and disclose conflicts of interest that might lead the mediator to benefit at the expense of the parties. ${ }^{86}$ In Comment 3, mediators should consider not serving in "situations where the mediator's ability to demonstrate Impartial Regard is compromised or appears to be compromised

78

See OREGON MEDIATION ASSOCIATION, supra note 6.

${ }^{79}$ See Coleman et al., supra note 9, at 683-84.

${ }^{80}$ See OREGON MEDIATION ASSOCIATION, supra note 6.

${ }^{81}$ Id.

${ }^{82}$ Id. at stds. III-IV.

${ }^{83}$ Id. at std. III.

${ }^{84}$ See id. In practice, mediator behavior will be affected by the mediator's training, rules governing practice in the jurisdiction, "best practices," ideology, and many other personal and situational factors. In some decision-making contexts, decision-makers prefer biased sources of information to neutral ones. Randall L. Calvert, The Value of Biased Information: A Rational Choice Model of Political Advice, 47 J. PoL. 530, 533 (1985). In the context of international disputes, highly biased, powerful interveners can induce agreements that unbiased third parties cannot, but in other contexts, impartial third parties behaving as mediator are more effective. See Katja Favretto, Should Peacemakers Take Sides? Major Power Mediation, Coercion, and Bias, 103 AM. POL. SCI. REV. 248 (2009).

${ }^{85}$ Susan Nauss Exon, How can a Mediator be both Impartial and Fair? Why Ethical Standards Create Chaos for Mediators, 2006 J. DiSP. RESOL. 387, 401-402 (2006).

${ }^{86}$ OREGON MEDIATION ASSOCIATION, supra note 6, at std. III, cmts. 1-2. 
because of the mediator's personal biases, views, or reactions to any position, argument, participant representative, or ... person. ${ }^{, 87}$ Likewise, a mediator who is over-focused on her reputation as one who settles cases could violate this Standard if she pushes for settlement in situations where the parties are not inclined to settle, but rather for the mediator's advocacy.

Similarly, Comment 3 on Standard 4 reads, "Mediators who meet with participants in private during mediation should not convey confidential mediation communications without the prior consent of the disclosing participant. ${ }^{\prime 88}$ The expectation in Standard 4 that a mediator will respect confidentiality as he or she creates communication channels does not guarantee against a mediator using strategically the information gained in confidence; that is, to influence either the process or the formulation of possible outcomes. To the extent that the parties can discover this and find it objectionable, their ability to withdraw mitigates the likelihood of a mediator doing it.

In sum, OMA's Standards of Practice operationalize everyone's incentives, including the mediator's, to use mutually agreed upon transaction resources efficiently, responding to the complex pressures and claims that arise. The Standards frame everyone's expectations about the mediator's application of transaction resources. Given everyone's ability to withdraw if they believe another is violating these expectations, the Standards provide common reference points for invoking a force of agreement. This resolves the divisible prisoner's dilemma between them, the second paradox, but perhaps the Standards should be more specific about the practical reality that the mediator's mere presence impacts the autonomy of the parties, adds costs, and influences both process and outcome.

\section{Collective Choice Theory and Paradox 3}

Collective choice theory (CCT) proves what SDT predicts: because both process and content impact the satisfaction of the three psychological needs, "covariation between content and process will typically occur." confirms that content and process-whether support, guidance, evaluation, or transformation-are inseparable. ${ }^{90}$ More correctly, guaranteeing their separation is impossible. Every group decision-making process is susceptible to manipulation by any participant, including the mediator. Indeed, parties do

\footnotetext{
${ }^{87}$ Id. at std. III, cmt. 3.

${ }^{88}$ OREGON MEDIATION ASSOCIATION, supra note 6, at std. IV, cmt. 4.

${ }^{89}$ Deci \& Ryan, supra note 8, at 246.

${ }^{90}$ Shapira, supra note 77.
} 
not always want to settle and might engage in mediation simply for strategic purposes. $^{91}$

Arrow's theorem, a mathematical proof, applies to any process that a group can design. ${ }^{92}$ Formally, Arrow started with a set of axioms about individual choice, which amounts to a definition of rational behavior, to design axioms about rational group choice. According to his proof, it is impossible to design a process for a group to make a choice that guarantees an outcome as rational as choices made by its individual members. ${ }^{93}$ This Third paradox is called Arrow's Paradox. Put differently, if a group reaches a durable process or substantive decision, as opposed to cycling indecisively among alternatives, we cannot guarantee that the group decision will be independent of the method by which it was chosen. ${ }^{94}$ Thus, process influences outcome.

Are Arrow's axioms plausible ${ }^{95}$ The axioms describing individual choice include:

- Connectivity (people can compare goods, services, or proposals; they can assess whether they prefer ice cream, cake, or candy)

- Transitivity (people can rank their preferences logically; if an individual prefers vanilla ice cream to chocolate, and chocolate to strawberry, then the individual will prefer vanilla to strawberry)

- Invariance (the ranking assigned to the most preferred alternative does not change if a less preferred alternative becomes unavailable; if an individual prefers vanilla to both chocolate and strawberry and also prefers chocolate to strawberry, then if strawberry is not available, the individual still prefers and will choose vanilla).

- Dominance (the order matters, not how much value one assigns to the items; on a hot day when any flavor of ice cream might provide more satisfaction than on a cool rainy day, the choice will be governed by the same ranking).

- Individual Decisiveness (the individual makes the ranking; no one else dictates the choice of flavor)

${ }^{91}$ Craig McEwen, Managing Corporate Disputing: Overcoming Barriers to Effective Use of Mediation for Reducing the Cost and Time of Litigation, 14 OHIO ST. J. ON DISP. RESOL. 1, 25 (1998).

${ }_{92}$ ARROW, supra note 3.

${ }_{93}^{93}$ Id.

${ }_{94}^{94}$ WILliAM RIKER, THE ART OF POLITICAL MANIPULATION 142 (1986).

95 JOHN BONNER, POLITICS, ECONOMICS, AND WELFARE: AN ELEMENTARY INTRODUCTION TO SOCIAL CHANGE, 56-71 (1986). 
This compact set of axioms, the basis for modern economics, seems uncontroversial, even necessary, to understand and predict individual decisions, including during mediation.

Arrow asked whether an analogous set of axioms can describe how a group reaches a decision. He proved that it cannot. If a group tries to decide which flavor ice cream all would order using a process in accord with these axioms, they likely would go hungry. If they leave with ice cream cones in hand, someone probably behaved in a way that violated one of the axioms.

On our analysis, CCT is consistent with Self-Determination Theory (SDT). CCT assumes individuals can be characterized by sets of values and tastes. In SDT, parties innately value competency, autonomy, and relatedness. CCT assumes that: (1) a set of alternative outcomes exists; (2) each party can rank them on one or more dimensions, and (3) the dimensions are standards for assessing the relevant properties of the outcomes. In SDT, the existence of alternative outcomes is part of the environment in which individuals act, given their competence in assessing the properties of the alternatives. CCT assumes individuals can exercise choice consistent with their preferences. In SDT, individuals make choices to satisfy their needs for autonomy, or their inward coherence, and competence, or their ability to attain valued outcomes. Finally, CCT establishes conditions under which a group will reach a decision without cycling interminably among alternatives, including the behavior by a mediator to help bring one about. In SDT, people value decisiveness over group indecisiveness because decisiveness promotes the senses of security and belonging that help to fulfill their need for relatedness. ${ }^{96}$

Being based in classical economics and concepts from non-cooperative game theory, CCT carries their inherent limitations. Economic theory cannot explain decisions by characterizing how individuals make interpersonal comparisons of utility, which in practice they do. We see it when parties arrive at solutions they perceive to be "fair" and refuse solutions that they perceive to be "unfair," even if both are made better off, something classical economics cannot fathom. That does not mean these decisions are irrational. It requires using different concepts of rationality, such as those in cooperative game theory. ${ }^{97}$ Nonetheless, CCT can inform our understanding of the risks parties take when mediators do what they do best, using tactics that can be shown in theory to violate one or more of Arrow's axioms.

${ }^{96}$ If a mediation process reinforces individual autonomy and competence, it might increase the likelihood of indecision. If a mediation process reinforces relatedness, making the utility of one party a function of the utility of another, it might reduce it.

${ }^{97}$ John C. Harsanyi, Cardinal Welfare, Individualistic Ethics, and Interpersonal Comparisons of Utility, 63 J. OF POL. ECO. 309 (1955). 
Arrow's Theorem thus presents the third of the three paradoxes bedeviling mediation. To experience it, the group need have as few as three people and three issues, which could describe even the simplest mediation that involves a mediator and two parties. The larger the number of parties involved, as in public policy matters, the more likely the outcome will follow from the rules of the process or be indecisive. ${ }^{98}$ If everyone knows this, why would anyone engage in any form of group decision-making, including mediation?

Yet, they do. Moreover, we observe mediation leading to decisions to participate. One reason people might participate is that the alternative processes are even more problematic. Another is that a mediator's tactics bring the group to agreement, albeit by testing, if not violating, one or another of the seemingly plausible axioms that Arrow imposes on the process. Nevertheless, the parties must find the cost of the mediator's behavior to be preferable to the alternative forms of intervention or nonintervention.

This brings us back to the OMA standards of practice and the need to agree on process to implement self-determination in mediation. ${ }^{99}$ Mediators should provide full disclosure for the participants to give informed consent. This will increase the chances of good faith participation and the mediator acting with impartial regard. The discussion surrounding the applicability of those mediator standards appears at the end of "Section III Common Mediator Tactics," below.

If Arrow is correct, "impartial regard" is contingent and affords mediators discretion. That is not necessarily a bad thing. It means that mediators are making tradeoffs, or, perhaps, simply recognizing a certain acceptance of and rationality in common, illogical decisions. The group gets a decision, for example, which has value independent of the merits of the decision. Mediators try to justify their acting instrumentally, but the Standards could make clear that a mediator's involvement in shaping the

${ }^{98}$ See ARROW, supra note 3. Arrow's result does not say that if a group of three or more reaches a decision, it has been dictated. It says that it is impossible to guarantee against someone strategically manipulating the process to arrive at a decision. One wonders whether a mediator respectful of the parties' need to feel competent, autonomous, and related should explain the implications of Arrow's work to the parties before inviting them to design their process. As it is, each participant is all too eager to assume that the other participant is the one being manipulative. Surely, explaining the implications of Arrow's work should make all of them unsure about participating in mediation. The issue for the mediator is whether she has an ethical obligation to explain this to the parties before they decide to mediate.

${ }^{99}$ OREGON MEDIATION ASSOCIATION, supra note 6. 
process and in framing arguments and proposals cannot help but be manipulative even when done with benevolent intent.

The next section outlines the strategic "manipulations" that are tools of the mediator's trade: A) Heresthetics (Political Strategy), and B) Rhetoric (Persuasive Discourse) ${ }^{100}$ We discuss them in the context of SDT, TRT and CCT, and the applicable ethical standards. The lesson of our analysis is that people should assess the risks of engaging in mediation, no matter how well intentioned. Well-crafted standards of practice minimize those risks.

\section{COMMON MEDIATOR TACTICS}

Of the three paradoxes, Arrow's may appear to be the least relevant to the practice of mediation. It might be the most difficult to fathom. However, it might be the most applicable, as well.

By way of elaboration, consider tactics mediators commonly employ to help parties in conflict. In our experience mediator "tactics" are often designed specifically to influence the choices, the ranking, and the intensity of preferences of the parties. When they use these tactics, mediators often refer euphemistically to "reality testing" or "balancing power." They tend to do this when they think a party is not thinking "correctly" about a topic. Mediators seldom find the need to do it when they agree with the parties.

We assign these tactics to two categories: heresthetic and rhetoric. Starting with heresthetics, we will explain why they work, which is to say, why they violate Arrow's axioms, and why the parties might allow mediators to manipulate them in these ways.

100

See Douglas Frenkel \& James Stark, Changing Minds: The Work of Mediators and Empirical Studies of Persuasion, 28 OHIO ST. J. ON DISP. RESOL. 263 (2013). Frenkel and Stark explore the research surrounding "persuasive effectiveness" in advertising, disease prevention, race relations and politics, and suggest similar research is needed in the context of mediation. They note that mediators "reframe" the word "persuasion" to "problem-solving," and suggest, as did Deborah Kolb and Kenneth Kressel, that mediators are prone to "engage in a "kind of denial about what they do." See Deborah M. Kolb \& Kenneth Kressel, The Realities of Making Talk Work, in WHEN TALK WORKS: Profiles OF Mediators 459, 483 (Deborah M. Kolb ed., 1994). We agree. Frenkel and Stark conclude mediation-specific research will inform the mediation field's views on the long-standing debates surrounding the mediator's necessary level of subject matter expertise to effectively mediate, and the iconic "facilitative-evaluative" debate we call "mischegas." 


\section{A. Heresthetic Tactics}

\section{Process Issues}

Heresthetics refers to "structuring the world so you can win." ${ }^{101}$ It is related to rhetoric but involves more that verbal persuasion. It involves setting up a situation so that other people will want or feel compelled by circumstances to cooperate, even without persuasion.

According to SDT and TRT, a mediator in support of self-determination should engage the parties in a collaborative discussion and ultimately a decision to select mediation and the mediator's approach. ${ }^{102}$ Assume two parties and the mediator try to decide on these. Their options are transformation, evaluation or facilitative; assume for simplicity that someone capable of implementing a "hybrid" approach is unavailable. ${ }^{103}$

Table 2 gives their preferences. They are rational. The mediator has preferences, too.

\begin{tabular}{|l|c|c|c|}
\hline \multicolumn{1}{|c|}{ Rank: } & First & Second & Third \\
Participant: & & & \\
\hline Party 1 & Evaluation & Facilitation & Transformation \\
\hline Party 2 & Facilitation & Transformation & Evaluation \\
\hline Mediator & Transformation & Evaluation & Facilitation \\
\hline
\end{tabular}

\section{Table 2}

Indeed, a practitioner of transformative mediation would want to empower the parties, reinforcing their self-determination by engaging them in designing the process-if that is what the parties want. ${ }^{104}$ If it was up to the disputants only, they have opposing preferences on transformation versus evaluation. They only agree that they both prefer facilitation to

${ }^{101}$ RIKER supra note 94, at ix. Heresthetics should not be confused with "heuristics," which are mental shortcuts that people use to solve problems and make judgments quicker and more efficiently. Heuristic, MERRIAM-WEBSTER, http://www.merriamwebster.com/dictionary/heuristic (last visited May 12, 2014). These "rules of thumb" can lead to cognitive biases.

${ }^{102}$ Samuel Imperati, If Freud, Jung, Rogers, and Beck were Mediators, Who Would the Parties Pick and What are the Mediator's Obligation?, 43 IDAHO L. REV. 645, 648 (2007).

$$
\begin{aligned}
& { }^{103} \mathrm{Id} \text {. at } 654-668 . \\
& \mathrm{Id} \text {. at } 655 .
\end{aligned}
$$


transformation. Still, they would not necessarily agree on facilitation because Party 1 prefers evaluation to that. They cannot decide.

Introduce the Mediator. At first glance, the three participants do not agree; none have the same first, second, or third choices. For the sake of simplicity, suppose that the three of them decide to take a straw poll following Robert's Rules. They might not use Roberts Rules in practice, but they'll use some sort of rule. According to Arrow, no rule is immune from sophisticated negotiators who often attempt to control the agenda, and as a result, the outcome. Even unsophisticated negotiators do it unintentionally when they set the agenda without manipulative intent. The following agendasetting options might be offered:

- Party 1's Proposed Agenda:

1) How many prefer facilitation to transformation? Two say, facilitation.

2) How many prefer evaluation to facilitation? Two say, evaluation. Result: Evaluation “wins” pursuant to Robert's Rules

- Party 2's Proposed Agenda:

1) How many prefer transformation to evaluation? Two say, transformation.

2) How many prefer facilitation to evaluation? Two say, facilitation.

Result: Facilitation “wins” pursuant to Robert's Rules.

- Mediator's Proposed Agenda:

1) The mediator asks how many prefer evaluation to facilitation? Two say, evaluation.

2) How many prefer transformation to evaluation? Two say, transformation.

Result: Transformation "wins" pursuant to Robert's Rules. ${ }^{105}$

The use of the Mediator's Proposed Agenda violates Standard 1 of OMA's Standards: Self-Determination and Standard 3: Impartial Regard. ${ }^{106}$ Indeed, according to OMA's Standards, the mediator would not have a vote, per se, which reduces the likelihood of cycling in a two-party mediation. However, not having a vote does not preclude the mediator from influencing the parties' approach selection. This brings us to the OMA Standards. A facilitative mediator might have explained the three alternatives first,

${ }^{105}$ Now, consider a fourth proposed agenda. 1) How many prefer facilitation to transformation? Two say, facilitation. 2) How many prefer evaluation to facilitation? Two say, evaluation. 3) How many prefer transformation to evaluation? Two say, transformation. The debate continues to "cycle" as noted above.

${ }^{106}$ OREGON MEDIATION ASSOCIATION, supra note 6. See also Imperati, supra note 102 , at 686-687. 
discussed them, and then sought agreement. However, the mediator would have to withdraw if the parties could not agree upon a process in a presession. If the mediator could bring them to agreement on using a transformative approach, even if for some reason one party did not want to use it, are they better off selecting this approach to continuing in conflict? Is it ethical for the mediator to do so?

\section{Substantive Issues}

What are mediators to do when they are discussing substantive agreements, especially when parties tend to seek and often look for or defer to the mediator's subject matter ${ }^{107}$ expertise? ${ }^{108}$ One option is for the mediator to seek mutual acceptance, which means that the parties can, at least, live with a proposed alternative, even if it is not their most preferred outcome. ${ }^{109}$ Another option is for the mediator to use her subject matter expertise to explain why one argument or position is more likely to prevail in front of the ultimate arbiter. To understand how mediators cannot help but be strategic manipulators, especially when it comes to substantive decisions, let us analyze this. ${ }^{110}$

First, a consensus approach is risky. Any party, even the mediator, can influence the group to accept an implied outcome, the status quo of going to trial, by finding every proposal on the table to be unacceptable. This violates

${ }^{107}$ OREgon Mediation Association, supra note 6. Standard V, "Process and Substantive Competence" states, "Mediators fully and accurately represent their knowledge, skills, abilities, and limitations. They mediate only when they offer the desired approach and possess the level of substantive knowledge, skills, and abilities sufficient to satisfy the participants' reasonable expectations." Id.

${ }^{108}$ Id. The term "subject matter expertise" is often used, but it is an exaggeration. The authors suggest "subject matter familiarity" better describes the requisite level of knowledge needed to meet the parties' reasonable expectations unless they prefer a highly evaluative approach.

${ }^{109}$ See LAWRENCE SuSSKIND \& JefFrey CRUIKSHANK, BREAKING RoBERT's RuLES (2006).

See e.g., Redress, UnITEd STATES POSTAL SERVICE http://about.usps.com/whatwe-are-doing/redress/welcome.htm (last visited Mar. 22, 2014) (describing the free, transformative program available to U.S. Postal Service employees). If mediators for the U.S. Postal Service offer disputants a choice between participating in the free REDRESS program, or the parties incurring the cost of a mediator who uses a different approach, they could be seen as dictating the decision by not offering as an alternative a different approach to mediation for free. 
Arrow's axiom that no single member of a group dictates the outcome. ${ }^{111}$ This is implied in any mediation. Standard 6: Good-Faith Participation in OMA's Standards militates against this. It exhorts mediators to "explain to the participants...that they can improve the mediation process and probability of success when they participate with an open mind throughout the process." 112 That implies not dictating the mediation approach or the substantive outcome.

Comment 1 encourages mediators to "promote honesty and candor" and to clarify for participants that the mediator is not a guarantor of participants' good faith. ${ }^{113}$ Coordinating expectations on the merits of agreeing to a mediation process versus not mediating has value. It carries little force, however, when a party does not participate in good faith.

Comment 2 encourages mediators to "discuss with the participants any concerns regarding Good-Faith Participation and the impact of these concerns on the process and the mediator's Impartial Regard."114 Comment 2 allows mediators to withdraw from the process when they feel their ability to demonstrate impartial regard has been compromised, imposing a cost on the participants who fail to participate in good faith by returning them to the status quo. Every party accepts this risk simply by agreeing to talk about engaging in mediation; in practice, that tends to happen.

Second, by the same reasoning, assuming that the parties agree upon mediation, a mediator with expertise or access to confidential information or both could, in theory, albeit with great ethical risk, induce a substantive agreement that might not achieve the level of "I can live with that." Suppose the mediator has legal expertise that the parties or attorneys do not and the mediator realizes they are considering an agreement far less equitable for one party than if they go to trial. This puts the mediator in the position, ethics aside, of preferring arguably no agreement, and, potentially, being able to set the agenda to secure it. Should the parties accept the risk of the mediator behaving in this manner?

OMA's Standards recognize the risk and seek to minimize it by setting out clearly defined expectations of mediator behavior. Comment 6 on Standard 2, Informed Consent, directs mediators to "make participants aware of the importance of consulting with other professionals to help them

${ }^{111}$ JOHN BONNER, POLITICS, ECONOMICS, AND WELFARE: AN ElEMENTARY INTRODUCTION TO SOCIAL CHANGE 62 (1986).

\footnotetext{
${ }^{112}$ OREGON MEDIATION AsSOCIATION, supra note 6, at std. 6.

${ }^{113}$ Id. at std. VII, cmt. 1.

${ }^{114}$ Id. at std. VII, cmt. 2.
} 
exercise Informed Consent and Self-Determination." ${ }^{115}$ Mediators' predictive legal expertise, if they have it, is less influential when the parties are represented by attorneys, but what if they are not and the parties select an "evaluative" approach? At a minimum, if parties have access to attorneys, mediators should advise the parties about the benefits of relying on their attorneys' advice. Mediators who prefer a substantive outcome risk violating Standard 3, ${ }^{116}$ Impartial Regard, if they act on that preference.

Third, if mediators gain information that helps them discern a basis on which the parties can reach agreement, not doing something risks the parties disagreeing, which is what most parties and mediators want to avoid. Identifying a single dimension ("interest" in the vernacular) underlying the parties' positions that they both care about more than their espoused positions is generally an acceptable mediator tactic to induce parties to reorder their preferences. The mediator reframes the problem so that a possible solution exists where one seems impossible before the reframing.

Economics treats individual preferences as given and, in that sense, invariant. If the parties cannot change their preferences, the process might well lead to no agreement or to cycling from one proposal to another. The mediator's tactic works because it violates an economist's assumption about the behavior of rational individuals participating in a collective choice. Most parties might agree that the risk associated with this tactic $-a$ form of manipulation-is benign or worth it to reach an agreement. In contrast, parties might not agree that the risk of another form of manipulation is so benign or worth it to reach an agreement: granting a mediator the latitude to induce cycling so as to increase their decision-making costs until they succumb to exhaustion and revise their preferences. ${ }^{17}$

Using information about the parties' different interests to help bridge gaps is another effective mediator tactic and likely a manipulation the parties would allow or even expect. For example, suppose a mediator learns that Party 1 prefers alternative "A" over "B" because of its cash value while Party 2 prefers " $B$ " over " $A$ " because of the impact Party 2 perceives it will have on his or her reputation, something Party 1 is less concerned about in this case. This could become the basis for an agreement, such as agreeing to " $\mathrm{A}$ " in exchange for including a confidentiality clause.

${ }^{115}$ Id. at std. II, cmt. 6.

${ }^{116} \mathrm{Id}$. at std. III.

117 Jeffrey Makoff \& Jessica Grynberg, "Private Caucusing" in Civil Pretrial Mediations, MEDIATE.COM (Nov. 2013), http://www.mediate.com/articles/MakoffJ1.cfm (showing how in practice, mediation participants anticipate that caucusing can lead to mediator manipulation in service of securing a deal-in fact, they plan their negotiation strategy accordingly by employing tactics such as anchoring and puffing). 
This violates one of Arrow's axioms about collective choice: only order of preference, not intensity of preference, matters. ${ }^{118}$ Indeed, intensity of preference matters. It creates opportunities for the mediator to help the parties explore solutions based upon their different intensities of preference. ${ }^{119}$ This helps establish relatedness while encouraging the parties' needs for competence and autonomy. Standards of ethical practice would not preclude this form of intervention if the parties agree to it and the mediator avoids violating impartial regard by not helping one party over another.

These are heresthetic techniques because the mediator restructures the decision consistent with the parties' true interests. Compared to the tactical disadvantages associated with the party sharing the same information directly with the opposing party, a mediator can more readily help the parties reveal this. In neither case do the bases for the initial disagreements disappear, but the result is agreement. In both cases, consistent with Arrow's concerns, either party has the potential to act in a disingenuous manner when revealing his or her interests as in a game of poker, influencing the final outcome. Standard 6 on Good-Faith Participation discourages, but does not guarantee it will not happen.

Particularly where parties with multiple interests underlying their positions engage in mediation, a variant on this mediator tactic is to reduce the number of issues by, for example, letting the parties vent over past indiscretions by the other party. Alternatively, the mediator encourages parties to acknowledge committing a past indiscretion, if not to apologize for it. This allows the parties to "get past" or eliminate historical "baggage," and focus on a smaller number of forward-looking issues whose ease of resolution increase the potential for "settlement" or "resolution." The former is acquiescence and the latter is acceptance. The fewer the issues, the less likely that the conditions exist for a paradox. The same holds for reducing the dimensionality of the decision-making by eliciting agreement among the parties on a compact, weighted set of criteria by which they will evaluate numerous proposed outcomes.

The ability of mediators to identify common interests and to exploit differences in intensity of preference; to help the parties craft intermediate alternatives between the simple paired "I win/you lose" choice; to reframe issues and underlying interests or their number; and to introduce decision tables explains some of the attractions of mediation. These and other

118 See JOHN BONNER, POLITICS, ECONOMICS AND WELFARE: AN ELEMENTARY INTRODUCTION TO SOCIAL CHOICE 59-60 (1986).

${ }^{119}$ See generally WISE DECIDER, http://wisedecider.net/user (last visited Feb. 24, 2014) (providing members access to decision tables that help with a wide range of decisions). 
heresthetic tools help groups make collective choices. Arguably, they are inconsistent with the Self Determination Standard.

The issue for the mediator is whether she has an ethical obligation to explain this dynamic to the parties before they decide to mediate. However, explaining the implications of Arrow's work would make all of them unsure about participating in mediation. We can do nothing or we can change the mediator standards to encourage mediators to explain this dynamic to the parties.

By creating expectations for all parties about acceptable behaviors, standards of practice give the mediator and the parties a degree of confidence that mediators will not abuse heresthetics, but are we giving sufficient information to the parties to ensure their informed consent? Perhaps mediator standards should require the mediator to explain what heuristic tools he uses during mediation, when, and how.

\section{B. Rhetorical Tactics}

\section{Theory}

As Booth puts it, "rhetoric makes realities," the classic distinctions among three kinds of "rhetoric-made" realities go to the heart of the mediator's craft:

- Forensic: "attempts to change what we see as the truth about the past," which is what mediators do to help the parties move from finding fault to finding solutions (e.g. the mediator might ask party A whether it is possible that party B's intent was something other than nefarious);

- Epideictic: "attempts to reshape views of the present," which is what mediators do to help the parties overcome misunderstanding, see the issues from different perspectives, and find common ground (e.g. the mediator might pose a choice to Party A - fix blame or fix the problem); and

- Deliberative: "attempts to make the future," which is what mediators intend to achieve (e.g. the mediator might posit to either party that it would be better to build a relationship than to fix blame). ${ }^{120}$

As opposed to heresthetics, where the rules matter, here, words and images reshape the past, present or future, reshaping "the personae of those ... who accept the new realities. You and I are remade as we encounter the remakings." ${ }^{211}$ Rhetoric does not necessarily elicit new information,

${ }^{120}$ WAYNe C. BoOTh, THE RHETORIC OF RHETORIC: THE Quest FOR EFFECTIVE COMMUNICATION 16-17 (2004).

${ }^{121}$ Id. at 17. 
which often is how a mediator adds value. Rhetoric has to do with changing people's minds by the presentation of information the parties may already have. $^{122}$

To Aristotle, deliberative oratory is the basis for community. ${ }^{123}$ Rhetoric capitalizes upon the human need for relatedness. Rather than persuading, in the sense of getting someone to do something they otherwise do not want to do, rhetoric is about a speaker (qua mediator) finding the best possible arguments. This tool works so long as the speaker addresses the concerns of the listeners (parties) and the decision to act is within the listeners' power. ${ }^{124}$ If used ethically, rhetoric capitalizes upon the human need for competence and autonomy.

The tactical arguments a rhetorician chooses include 1) syllogisms, 2) deductive arguments with three propositions, and 3) arguments by example, which are variations of enthymemes. An enthymeme is an argument that not only leads to a logical conclusion, but also leads to a decision through individual volition. Examples include summarizing points with a forceful climax (accumulation), arguing a topic from both sides to help parties gain a deeper under-standing of an issue (dissoi logoi), and repeating the same point with different but parallel words and referents to emphasize its significance (exergasia).

Aristotle ${ }^{125}$ divides rhetorical arguments into three not mutually exclusive categories in terms of their ability to appeal to an audience and move it to action:

- Logos: an appeal based on logic, or to the intellect, can include theory, statistics, and expert opinion. When a mediator invokes logic, it can stimulate a change in position by satisfying a party's psychological need to feel competent. Such an argument may be particularly effective in helping parties solve coordination problems.

- Ethos: an appeal based on ethics, such as the credibility and trustworthiness of the speaker, is a determination made by the audience. By invoking, for example, virtue and goodness, the mediator speaks to an accepted communal value and can stimulate a positional change by satisfying a party's need to feel related and of good character. That may be particularly effective in helping parties solve enforcement problems.

${ }^{122}$ See Enriqueta Aragones et al., Rhetoric and Analogies (Penn Inst. for Econ. Research, Working Paper No. 13-039, 2013).

${ }^{123}$ WENDY OLMSTED, RHETORIC: AN HISTORICAL INTRODUCTION 11 (2006).

${ }^{124}$ Id. at $13-14$.

${ }^{125}$ See generally ARISTOTLE, ON RHETORIC: A THEORY OF CIVIC DISCOURSE 37-38, (George A. Kennedy trans., 1991). 
- Pathos: an appeal based on sympathy, emotion, and feeling without necessarily analyzing the rationale, can include figurative or vivid language and emotional narratives. By invoking, for example, anger, fear, empathy, or compassion to connect with personal experiences, the mediator can stimulate a change in position by satisfying a party's need to feel autonomous. Such an argument might seem to be particularly effective in helping parties solve division problems by normalizing their reactions. By allowing parties to feel reasonable and heard, the chances increase that they will let go of any counterproductive baggage that inhibits their agreeing. ${ }^{126}$

The theory of rhetoric is consistent with SDT because both incorporate competence, relatedness, and autonomy as motivations for decision-making.

SDT and CCT both have extensive theoretical and empirical support for their explanatory powers. Rhetoric is primarily theoretical, but behavioral economics buttressed by neuroscience provides empirical support for it. ${ }^{127}$ Analogously to heresthetics, choices cannot be presented neutrally; any presentation can influence the decision maker's choice. ${ }^{128}$ Restated, a mediator can use rhetoric to create or inhibit self-determination.

\section{Tools}

Rhetoric and behavioral economics presume that psychological biases abound and that people use heuristics to simplify their decision-making. Rhetoric can exploit this in both the positive and negative senses of the term. We cannot establish a one-to-one correspondence between every rhetorical technique and every finding documented by behavioral economists. However, we can find substantial correspondence, particularly with respect to rhetorical tactics, that mediators commonly use and that are designed to help the parties, not to trick them.

One example of such a rhetorical tool is this: rationality presumes that people make identical choices over identical options, regardless of how the options are described. ${ }^{129}$ In reality, people perceive outcomes in terms of

${ }^{126} \mathrm{Id}$.

${ }^{127}$ See generally DANIEL KAHNEMAN \& AMOS TVERSKY, JUDGMENT UNDER UNCERTAINTY: HeURISTICS AND BIASES, (Daniel Kahneman, Paul Slovic, \& Amos Tversky eds., 1982); Richard Birke, Neuroscience and Settlement: An Examination of Scientific Innovations and Practical Applications, 25 Оніо ST. J. ON DISP. RESOL. 477, 501-23 (2010).

${ }^{128}$ Eric J. Johnson et al., Beyond Nudges: Tools of a Choice Architecture, 23 MARKETING LETTERS 487, 488 (2012).

${ }^{129}$ Amos Tversky \& Daniel Kahneman, Rational Choice and the Framing of Decisions. 59 J. Bus. S251, S253 (1986). 
value defined over gains and losses relative to some reference point that they usually intuit and can only vaguely articulate as in, "it just feels right." Gains and losses display diminishing sensitivity (i.e., the difference between $\$ 10$ and $\$ 20$ seems bigger than the difference between $\$ 100$ and $\$ 110$ ), and losing a fixed amount hurts more than gaining the same amount. ${ }^{130}$ Suppose a disputant frames an argument or a proposal in terms of capturing a potential gain. A mediator might summarize the proposal as made, or reframe it using words that describe it as avoiding a potential loss, which is more likely to induce, or otherwise persuade, the other side to accept the proposal, even if it involves making a concession. ${ }^{131}$

Alternatively, suppose a disputant were to make a series of proposals with multiple costs and benefits. People often employ a type of mental accounting that assigns value into two categories: good (revenues) or bad (expenditures). ${ }^{132}$ In short, money is not fungible, as classic rationality assumes. "Money in one mental category is not a perfect substitute for money in another....,"133

A mediator's decision to pool the proposals into a package rather than deal with them serially is a heresthetic technique. Summarizing them in terms of their total net impact rather than presenting them one-by-one is a rhetorical technique (akin to accumulation). It can influence the disputants' perceptions and, hence, their decisions. A closely related rhetorical tactic mediators employ for the same reason is to re-order the elements of a proposed package so the listeners hear first an element they probably like, then one not so likable, and closing with one they will really like. ${ }^{134}$ An analogous rhetorical tactic involves the National Coalition Building Institute's ${ }^{135}$ "umbrella question" technique, where the mediator teases out the different interests of the parties, establishes their legitimacy, pools them, and asks how all can be satisfied while achieving a collective goal.

${ }^{130}$ Richard Thaler, Mental Accounting Matters, 12 J. BeHAV. DEC. MAKING 183, 185 (1999).

See generally AMOS TVERSKY \& DANIEL KAHNEMAN, Loss Aversion in Riskless Choice: A Reference-Dependent Model, 106 Q. J. ECON. 1039 (1991).

${ }^{132}$ Id. at 184.

${ }^{133}$ Id. at 185 .

${ }^{134}$ This tactic relies on the concepts of primacy and recency as we tend to react more strongly, and thus are overly influenced by things we hear first and last. See RoBIN HOGARTH, JUDGMENT AND CHOICE 55 (2d ed., 1987).

${ }^{135}$ See generally NATIONAL COALITION BUILDING INSTITUTE, http://ncbi.org (last visited Mar. 23, 2014). Mediators structure umbrella questions as follows: "How can we achieve [list party A's interests] while at the same time addressing [party B's interests], thereby achieving [list interests common to A and to B]?" 


\section{B. Mediator Ethical Challenges with Heuristics and Rhetoric}

In sum, rhetorical tactics, like heresthetic ones, impart power to mediators. Every mediator action exercises some form of power whether the mediator wants to acknowledge it or not. With all of the opportunities for mediators to influence the process and outcome, even unintentionally, how is it possible for parties in conflict to engage in mediation, motivated by their pursuit of personal autonomy, competence, and relatedness, without undermining their raison d'etre for participating? The answer is the faith they place in standards of ethical practices, like OMA's, and the belief that exercising reasonable discretion will allow the mediator to bring the parties to an agreement more efficaciously than if they employed alternative processes. The challenge thus becomes whether the current schema for ethical practices in mediation are sufficiently detailed and robust to justify the parties faith in mediation.

\section{CONCLUSIONS AND RECOMMENDATIONS: CRAFTING STANDARDS OF ETHICAL PRACTICE}

\section{A. Overview of Conclusions and Recommendations}

\section{Conclusions}

a. The following mediation field's common assertions are arguably erroneous: A) parties own the outcome; mediators own the process, and B) mediators have no preferences over outcomes.

b. Mediation works because of a mediator's judicious (ethical) application of heresthics and rhetoric to serve the participants', including the mediator's, psychological needs for selfdetermination and efficient use of transaction resources.

c. Parties and a mediator who agree on ethical standards of practice satisfy their intrinsic needs, reinforcing self-determination; solve a divisible prisoner's dilemma problem at low cost; and mitigate manipulation.

\section{Recommendations}

a. Mediators should create robust standards of ethical practice because that can resolve all three paradoxes. 
b. Robust standards of ethical practice should require the mediator to engage the parties in a pre-negotiation exploration of the mediator's tools and their potential impact on the process and the outcome.

c. Parties in mediation should inquire about and agree to the ethical standards to which the mediator adheres.

d. Mediators should make standards of ethical practice mandatory to encourage mediation. While mostly aspirational, current standards reduce the parties' fears by establishing expectations of reasonable behavior.

e. Mediators should evaluate and implement meaningful enforcement mechanisms, which are not prevalent in the field, including the pursuit of disciplinary claims. Should we not hold ourselves accountable when we violate ethical standards? It is done in other professions. Thus, mediators who charge a fee should not be immune from malpractice, but instead, should be held to the typical professional negligence standard.

Each of the above recommendations is developed below.

First, mediators should create robust, realistic standards of ethical practice because public standards reduce the costs to the parties of identifying unacceptable behavior by the mediator. They put the burden on the mediator to avoid strategic behavior in the form of inappropriate heresthetic or rhetorical maneuvers, or to use them only when clearly justified. ${ }^{136}$ Standards of ethical practice should validate the parties' expectations about how the mediation will be conducted, codifying the reasons why parties could give a mediator a bad reputation. ${ }^{137}$ If the parties can discharge a mediator for violating ethical canons, and if mediators by terminating a mediation self-enforce those canons, ethical canons help solve the coordination problem, reducing the costs of resolving the prisoner's dilemma between disputants and the mediator. The parties then have more internal transaction resources to apply to resolving their substantive dispute.

${ }^{136}$ Shapira, supra note 77 , at 39-45.

${ }^{137}$ OREGON MEDiation Association, supra note 6, at std. III, cmt. 4. The standard specifically notes that "[m]ediators should not influence participant decisions because of the mediator's interest in higher settlement rates, increased fees, or non-participant pressures from court personnel, program administrators, provider organizations, the media, the public, or others." Id. This is another example of the requisite level of specific guidance standards should provide. Making that provision enforceable would provide even more confidence in the mediation process. 
Beyond serving the parties, standards of ethical practice serve mediators. Ethical standards help define what it means for a mediator to be autonomous, competent, and related, just as they serve the purposes of participants who have the same psychological needs. Not surprisingly, empirical research finds that the mediators who engage in behaviors associated with reinforcing their own and the parties' autonomy, competence, and relatedness encourage trust by the parties in mediators. ${ }^{138}$

Second, our analysis provides guidance for those who are creating or revising standards of practice by identifying questions the writers should address. For example, to secure "High Quality Consent"139 and "Procedural Justice," ${ }^{140}$ how detailed, if at all, should the mediator explain the implications of SDT, TRT, and CCT? Standards separating process selection from outcome, or non-substantive from substantive issues, defy theory and reality.

Likewise, should mediators take these concepts to the concrete level and engage the parties in a pre-mediation conversation about how specifically the mediator is to act or refrain from acting? Topics ${ }^{14}$ could include: 1) Will we use a transformative, facilitative, evaluative, hybrid, or some other model for this mediation? What do these terms mean to you? Can the model change, and, if so, under what circumstances? 2) Should the mediator raise issues, claims, or defenses? Under what circumstances? 3) Should the mediator offer opinions? If yes, under what circumstances? 4) To what extent, if any, should the mediator use information received confidentially as a tactic to bring parties together? 5) Should the mediator tell the parties what heuristic and rhetorical tools he will use, when and how?

Third, potential users should inquire as to what ethical standards, if any, a potential mediator adheres to before they agree to mediation. ${ }^{142}$ Transaction

${ }^{138}$ See generally Jean Poitras, What Makes Parties Trust Mediators?, 25 NEgotLATION J. 307 (2009).

${ }^{139}$ John Lande, How Will Lawyering and Mediation Practices Transform Each Other?, 24 FLA. ST. U. L. REV. 839, 857 (1997).

${ }^{140}$ Nancy Welsh, Making Deals in Court Connected Mediation: What's Justice Got to do with it? 79 WASH. U. L. Q. 787, 817 (2001).

${ }^{141}$ Sam Imperati, Mediator Practice Models: The Intersection of Ethics and Stylistic Practices in Mediation, 33 WILLAMETTE L. REV. 703, 742 (1997).

${ }_{142}$ OrEgON MEDIATION Association, supra note 6. Standard X, Mediation Practice, Comment 13 states, "Mediators should provide these Core Standards to the mediation participants as soon as practical." Id. The authors suggest this is an example of the requisite level of specific guidance standards should provide. General philosophical principles are not always sufficient to give participants the full disclosure necessary for informed consent and self-determination. Making such provisions enforceable would lead to even more confidence in mediation. 
Resource Theory predicts that parties in conflict will use a third party if they believe that the benefits exceed the costs, including the risks we have identified. They must first agree to mediate, believing that the process will minimize the risks of process and outcome manipulation, usually by the other parties. Indeed, they might believe that it will because they view the mediator as the guardian of process fairness. This could be naïve, albeit preferable to engaging in alternative processes. Mediators are not neutral, even if they act with impartial regard, because they have points of view, especially about the process, but they should avoid acting on them to the substantive disadvantage of the parties. Mediators who adhere to ethical standards that do not speak to these concerns to the satisfaction of the parties, or who do not adhere to any ethical standards, should give the parties pause about engaging with that mediator.

Fourth, standards of ethical practice should be mandatory, providing the potential for a robust check and balance system enforced by professional associations or the courts. Our analysis supports the need for something beyond reputation effects to enforce everyone's expectations that mediation can be successful while allowing all of the parties to be self-determining. Before reaching the substantive issues and whether everyone will abide by terms of any agreement, the parties must solve a preliminary problem about the legitimacy of the process and the mediation approach they will use. The key is the enforceability of mediator standards of ethical practice.

Fifth, with robust, value-based, realistic and mandatory standards of practice in place, mediators should evaluate and implement meaningful enforcement mechanisms, which are not prevalent in the field. ${ }^{143}$ This step introduces the matter of a complaint process and the potential for a mediator malpractice claim. If a mediator behaves unethically, the mediator likely committed malpractice, assuming there were damages caused by the error or omission. Mediators can be guilty of malpractice without being unethical if their behavior falls below the standard of care in the profession, which presents the prima facie case for mediators to create standards of care. Oregon mediators are immune, however, "unless the act or omission was made or done in bad faith, with malicious intent or in a manner exhibiting a willful, wanton disregard of the rights, safety, or property of another."1144 A mediator merely negligent is immune.

${ }^{143}$ Carrie Menkel-Meadow, Regulation of Dispute Resolution in the United States of American: From the Formal to the Informal to the 'Semi-Formal', in REGULATING DisPUTE RESOLUTION: ADR AND ACCESS TO JUSTICE AT THE CROSSROADS 419, 444 (Felix Steffek \& Hannes Unberath eds., 2013).

${ }^{144}$ OR. REV. STAT. $\$ 36.210$ (2013). 
Thus, mediators who charge and receive a fee ${ }^{145}$ should not be immune from malpractice, but instead, should be held to the typical professional negligence standard, especially when malpractice insurance is readily available. ${ }^{146}$ States or self-governing organizations like OMA could also enforce ethical standards of practice by holding mediators accountable when they violate ethical standards as is done in other professions. ${ }^{147} \mathrm{As}$ it stands, OMA's complaint process is voluntary and non-binding, which on our analysis using SDT, TRT and CCT, is insufficient. Features of mediation that make it so attractive, such as party self-determination, procedural choice, and confidentiality, create informational deficits that justify licensure. ${ }^{148}$

\section{B. Improvement Process Plan}

At a bar association continuing legal education class, ${ }^{149}$ a federal trial judge and a jury consultant explored how litigators can best present their cases to juries. They explained several rhetorical tools and cognitive biases, ${ }^{150}$ with suggestions on how trial attorneys can use them or overcome them to their persuasive advantage. Examples included: A) "Don't Bury the Lead," meaning lead with your point, and then, backfill with the train of logic and facts that got you there, not the other way around; and B) "Don't take the bait," meaning never directly respond to your opponents framing of

${ }^{145}$ OREgON MEDIATION ASSOCIATION, supra note 6. Standard X, Mediation Practice, Comment 8 states, "Mediators who charge a fee are encouraged to have malpractice insurance." $I d$. The authors suggest the time has come to mandate insurance, not just encourage it. See State by State, Mandatory Malpractice Disclosure Gathers Steam, AMERICAN BAR ASSOCIATION, http://www.americanbar.org/publications/bar_leader/ 2003_04/2804/malpractice.html (last visited Apr. 18, 2014). It is a tenet of professionalism that clients are the first priority and they need to be protected.

${ }^{146}$ Pinkham Insurance Program, Association fOR CONFLICT RESOlution, http://www.acrnet.org/Page.aspx?id=664 (last visited Apr. 18, 2014).

${ }^{147}$ See History of Mediation in Oregon: Certification, Licensure, and Enhancing Mediator Competency, OREGON MEDIATION ASSOCIATION (Feb. 4, 2014, 2:30 PM), http://www.omediate.org/pg1 122.cfm (last visited Apr. 18, 2014).

${ }^{148}$ But see Felix Steffek et al., Guide for Regulating Dispute Resolution (GRDR): Principles and Comments, in REGULATING DISPUTE RESOLUTION: ADR AND ACCESS TO JUSTICE AT THE CROSSROADS 13, 25-26 (Felix Steffek \& Hannes Unberath eds., 2013).

${ }^{149}$ Hon. Michael Simon \& Christopher Dominic, Science of the Mind: How Jurors, Judges and Other Key Decision Makers Really Think, MULTNOMAH BAR Association (Mar. 4, 2014), https://www.mbabar.org/education/watch-archived-cle-webcast/scienceof-the-mind.

${ }^{150}$ Kendra Cherry, What is a Cognitive Bias? Mental Mistakes and Errors, AвOUT.COM http://psychology.about.com/od/cindex/fl/What-Is-a-Cognitive-Bias.htm. 
the story; always reframe it by telling your story. These tactics were enthusiastically received by the audience.

Over the years, lawyers have discussed a duty of zealous advocacy (representation) on behalf of their clients. ${ }^{151}$ Mediators have no such duty; in fact, their duties are to display neutrality/impartial regard. This is why mediators, regardless of their profession of origin, should struggle with the resulting ethical issue associated with using rhetorical tactics, while the lawyers do not. It also might explain why lawyers representing parties in mediation or acting as a mediator can be desensitized to the appropriate or inappropriate use of rhetoric-it seems so familiar, and therefore, so acceptable to them. This is a "cognitive bias." It is called, "Mere Exposure Effect," the tendency for parties to express undue liking for things merely because they are familiar to them. ${ }^{152}$ This justifies training for everyone engaged in mediation. ${ }^{153}$

At a conference on conflict management, ${ }^{154}$ practitioners, largely made up of as psychologists and social workers, objected to mandatory standards of ethical practice and competency. The people (presumably lawyers) who write laws, they said, would write standards to exclude non-lawyers from serving as mediators. Nothing in OMA's standards would do so. No matter. The irony should not be lost: mediators with different backgrounds who find their legitimate interests to be in conflict not only eschew an authoritative statutory process for setting standards that might benefit their profession, they evidently fail to consider mediation as a basis for crafting a statutory solution. It seems we cannot even resolve these issues within our own field. Perhaps, we should convene a public policy facilitation, invite mediation users, and see what they think. For the good of potential clients, mediators should practice what they preach: full disclosure, informed consent, and the promotion of self-determination.

${ }^{151}$ See Sylvia Stevens, Whither Zeal?, OREGON STATE BAR (Jul. 2005), http://www. osbar.org/publications/bulletin/05jul/barcounsel.html (last visited Apr. 18, 2014).

${ }^{152}$ Gillian Fournier, Mere Exposure Effect, PsYCHCENTRAL, http://psychcentral. com/encyclopedia/2009/mere-exposure-effect/ (last visited Mar. 12, 2014).

${ }^{153}$ For a beta version, user-friendly summary of cognitive biases, see Eric Fernandez, A Visual Study Guide to Cognitive Biases, UNIVERSITY OF NEW MEXICO, http://www.cs.unm.edu/ jmk/cognitive_bias.pdf (last visited Apr. 18, 2014). Interestingly, numerous mediator impasse-breaking techniques "work" because they attend to the cognitive biases of the parties.

${ }^{154}$ See generally 26th Annual IACM 2014 Conference, INTERNATIONAL ASSOCIATION FOR CONFLICT MANAGEMENT (Jul. 2013), http://www.iacmconflict.org/sites/default/files/2013_IACM_Conference_Program_Web.pdf. 
The authors have observed and participated in robust debates, probably unconsciously influenced by "deformation professionalle," 155 over what profession(s) of origin "own" mediation. Moreover, let us not forget the internecine debates about facilitative-transformative-evaluative mediation approaches. With the playful hope of provoking more friendly discussion, dare we get complacent, if attorneys, acting as advocates or mediators, are desensitized to dangers of rhetorical tactics, they have a blind spot when they become mediators. Parties should be cautious, unless, of course, mediators must be licensed and licensure requires training that re-sensitizes them to the implications of using rhetorical tactics. Conversely, mediators from other professions of origin should be sensitized to their blind spot-the fact that laws are nothing more than society's codification of fairness norms surrounding appropriate and inappropriate behavior. Laws are based upon commonly accepted values and needs- "interest" in mediation vernacular. If nothing else, the authors hope this article motivates more discussion about what mediators should understand before they mediate and what parties should know before they agree to mediate "on faith." 156 So, what are we going to do to improve the wonderful field of mediation? At a minimum, mediators should critically explore the dissonance between what we say at conferences/trainings and the ethical and practical impact of what we actually do in the field. This requires self-reflective, and dare we say, "transformative" training to transparently operationalize the core principles of mediation.

${ }^{155}$ This is the tendency to look at things according to the conventions of one's own professions, forgetting any broader point of view. See ALEXIS CARREL, L'HOMME, CET INCONNU 43 (1935).

${ }^{156}$ We are not using the "decoy effect" cognitive bias. That is the tactic where the preferences for either option A or B changes in favor of option B when option C is presented, which is similar to option B but in no way better. See generally Shankar Vedantam, The Decoy Effect, or How to Win an Election, THE WASHINGTON POST (Apr. 2, 2007), http://www.washingtonpost.com/wp-dyn/content/article/2007/04/01/AR20070 40100973.html. The mediation field should explore training mediators and parties even if it decides to keep the current ethical and enforcement constructs. 